\title{
TRES APORTES FUNDAMENTALES DE EL FEDERALISTA A LA TEORÍA CONSTITUCIONAL MODERNA
}

\author{
José Francisco García García*
}

\begin{abstract}
RESUMEN
El presente documento tiene por objeto analizar tres aportes fundamentales que realiza la obra El Federalista a la teoría constitucional moderna. En primer lugar, se analiza el sentido mismo de la Constitución, que para los autores importa la configuración de poderes públicos limitados; en segundo lugar, la necesidad de contar con un Poder Judicial fuerte e independiente que se constituya en "fiel guardián" de la Constitución, garantizando los derechos y libertades de los individuos; y, finalmente, que el Judicial tenga asimismo la facultad de controlar la constitucionalidad de la legislación -judicial review of legislation-para asegurar el principio de supremacía constitucional.
\end{abstract}

\section{EL FEDERALISTA - PODER JUDICIAL - CONTROL DE CONSTITUCIONALIDAD}

\section{Fundamental contributions of The Federalist to modern constitutional theory}

\begin{abstract}
This article aims to analyze the three most fundamental contributions the work "The Federalist" has made to modern constitutional theory. Firstly, this paper examines the very meaning of Constitutions, which, for its authors, involved the establishment of limited public powers; secondly, the need to have an independent and strong Judicial Power, constituted as a "faithful guardian" of the Constitution, guaranteeing the rights and freedoms of the individuals; and, finally, the fact that, in addition, the Judiciary must have the ability to control the legislation's constitutionality (judicial review of legislation), in order to ensure the principle of Constitutional Supremacy.
\end{abstract}

THE FEDERALIST - JUDICIAL POWER - JUDICIAL REVIEW

* Abogado, Licenciado en Derecho, Master en Derecho, Coordinador del Programa de Justicia de Libertad y Desarrollo y Profesor de la Facultad de Derecho, Pontificia Universidad Católica de Chile. E-mail: jfgarcia@lyd.org, Dirección: Alcántara 498, Las Condes, Santiago de Chile. Artículo recibido el 26 de septiembre de 2006 y aceptado para su publicación por el Comité Editorial el 4 de mayo de 2007. 


\section{INTRODUCCIÓN}

$\mathrm{L}$ as sociedades modernas se caracterizan por su apego al imperio del derecho o al respeto del "gobierno de las leyes y no de los hombres" en la formulación liberal. poder del Estado y protegen los derechos y libertades de las personas, estableciendo con claridad el marco de ejercicio de estas. ${ }^{1}$ Ello requiere de un Poder Judicial independiente que pueda cumplir con el rol que le entregan la sociedad y la Constitución: garantizar dichos derechos y libertades, evitar la autotutela y entregar certeza jurídica a los individuos. Asimismo, se requiere de mecanismos institucionales, preferentemente de naturaleza jurídica, que tanto en el derecho como en los hechos garanticen que la Constitución no sólo parezca sino sea la ley fundamental.

Así las cosas, las cuestiones recién planteadas constituyen el objeto central del presente documento, en la medida que pasan a ser tres aportes fundamentales que realiza la obra El Federalista ${ }^{2}$ a la teoría constitucional moderna. En este sentido, y en primer lugar, se analizará el sentido de la Constitución para El Federalista. En segundo lugar, se verá por qué sus autores asignan tanta importancia al Poder Judicial y, más aún, al diseño institucional de este. Finalmente, y estrechamente vinculado a lo anterior, se analizan los motivos por los cuales Hamilton, Madison y Jay creen fundamental contar con un sistema de control de la constitucionalidad de las leyes -judicial review of legislation-como, asimismo, por qué esta facultad debe estar radicada en el Poder Judicial.

\footnotetext{
${ }^{1}$ Siguiendo a los contractualistas Locke y Hobbes, la idea misma de Estado refleja un pacto entre los ciudadanos para asegurar la mejor protección de los derechos y libertades de los individuos. Así, se le pide al Estado como mínimo velar por el orden interno y la administración de justicia, precisamente para evitar la autotutela.

${ }^{2}$ El Federalista, o The Federalist Papers, es una serie de ochenta y cinco artículos escritos entre octubre de 1787 y mayo de 1788. Los ensayos fueron publicados simultáneamente en varios periódicos del Estado de Nueva York, en forma anónima, bajo el seudónimo de Publius. El Federalista se escribió y publicó para incitar a los ciudadanos de Nueva York a ratificar la Constitución de los Estados Unidos, que había sido redactada en Filadelfia durante el verano de 1787. Al urgir la adopción de la Constitución por encima de los Artículos de Confederación ya existentes, los textos explican ciertas disposiciones de la Constitución en detalle. Por esta razón, El Federalista se utiliza a menudo hoy para ayudar a interpretar las intenciones de quienes redactaron la Constitución de los Estados Unidos. Desde la fecha de su publicación se les ha considerado como los más perfectos comentarios existentes sobre el significado y la naturaleza de la Constitución de los Estados Unidos. Así, Thomas Jefferson, por ejemplo, creía que representaban "la opinión general de los que la redactaron y de los que aceptaron la Constitución de los Estados Unidos, en asuntos relativos a su genuino significado”. Sin embargo, resulta aún más reveladora la estimación de Jefferson en otro contexto: a saber, él creía que era "el mejor comentario sobre los principios de gobierno que se haya escrito jamás”. Ambas citadas en Liggio, L., "The Life and Works of Thomas Jefferson", en The Locke Luminary Vol. II, No 1 (Summer 1999). Fue quizás George Washington el que mejor fijó su lugar entre los clásicos al escribir que "merecía la atención de la posteridad porque ahí se analizan francamente los principios de la libertad y los tópicos del gobierno que resultarán siempre de interés para la humanidad, mientras el hombre esté relacionado en la sociedad civil". Para este y otros comentarios por eruditos y estadistas respecto de El Federalista ver Dietze, G., The Federalist: A Classic on Federalism and Free Government, John Hopkins Press, Baltimore, 1960, Capítulo 1.
} 
El sentido más profundo de este documento es rescatar el aporte que realiza esta obra al desarrollo de instituciones jurídicas fundamentales de nuestra institucionalidad, en particular del diseño constitucional, acercando a la cultura jurídica nacional una obra que, sea por provenir desde un origen legal distinto al nuestro (common law) o porque la doctrina constitucional local ha puesto históricamente sus ojos en el constitucionalismo europeo, ha pasado, injustamente a nuestro juicio, prácticamente desapercibida y ha sido escasamente analizada y citada en las discusiones del derecho político y constitucional chileno.

\section{El SENTIDO DE LA CONSTITUCióN}

¿Cómo la Constitución limita el poder del Estado y, por lo tanto, garantiza los derechos y libertades de las personas? La respuesta inmediata y natural sería la existencia de una Declaración o "Catálogo" de Derechos, que por estos días aparece como la parte más visible de la Constitución. ${ }^{3}$ Históricamente, las declaraciones de derechos han sido "estipulaciones entre reyes y sus sujetos, prerrogativas en favor de privilegios, tales como la Carta Magna y la Declaración de Derechos inglesa de 1689”, "y sus términos se han hecho cumplir, si es que lo han sido, por el poder político que han alcanzado las asambleas populares. Así, y en respuesta a la interrogante recientemente planteada, surge El Federalista como un intento de determinar cómo un diseño constitucional exitoso es capaz de limitar el poder de quienes lo detentan, para así garantizar los derechos y libertades de sus individuos y, lo más importante, a través de qué medios se puede realizar esta tarea.

En este sentido, la primera respuesta o aproximación a este tema de los Federalistas -Madison, Hamilton y Jay- es que una Declaración de Derechos por sí sola no es capaz de realizar esta tarea. De esta forma, resulta más que necesario reconsiderar los argumentos entregados por estos autores en contra de la inclusión de una Declaración de Derechos en la Constitución. Incluso sin las diez primeras enmiendas, argumentó Hamilton en El Federalista $\mathrm{N}^{\circ}$ 84: "La Constitución forma por sí misma UNA DECLARACIÓN DE DERECHOS, en el sentido verdadero de ésta y para todos los efectos beneficiosos que puede producir". 5

La razón por la que en principio los Federalistas decidieron no incluir una Declaración de Derechos en la Constitución y las consideraciones que más tarde persuadieron incluso a aquellos que en principio se habían opuesto a tal decisión, son igualmente significativas. El argumento en contra de la inclusión fue expuesto explícitamente en El Federalista

${ }^{3}$ La creencia de que los derechos son mejor garantizados cuando están previamente definidos y enumerados en una lista cuidadosamente preparada se refleja en la controversia actual de si acaso cabe incluir nuevos derechos (eutanasia, aborto, sociales, etc., o en una clasificación más reciente, derechos humanos de tercera y hasta cuarta generación) al catálogo inicial de derechos políticos y civiles.

${ }^{4}$ Hamilton A. y otros, ob. cit., $\mathrm{N}^{\circ} 84$, p. 367.

${ }^{5}$ Idem., $\mathrm{N}^{\circ} 84$, p. 369. 
No 84: "Las Declaraciones de Derechos, en el sentido y con la amplitud que se pretenden, no sólo son innecesarias en la Constitución proyectada, sino que resultarían hasta peligrosas. Contendrían varias excepciones a poderes no concedidos y por ello mismo proporcionarían un pretexto plausible para reclamar más facultades de las que otorgan. ¿Con qué objeto declarar que no se harán cosas que no se está autorizado a efectuar? Por ejemplo: ¿para qué se afirmaría que la libertad de prensa no sufrirá menoscabo, si no se confiere el poder de imponerle restricciones? No es que sostenga que una disposición de esa clase atribuiría facultades de reglamentación; pero es evidente que suministraría a los hombres con tendencias usurpadoras una excusa atendible para reclamar ese poder. Podrían argumentar con cierta apariencia de razón que no se debe imputar a la Constitución el absurdo de precaverse contra el abuso de una potestad que no existe y que la disposición que prohíbe limitar la libertad de la prensa autoriza claramente a inferir la intención de dotar al gobierno nacional de la facultad de prescribir normas apropiadas en el caso de dicha libertad. Esto puede servir de ejemplo de los numerosos asideros que se ofrecerían a la doctrina de los poderes de interpretación si se transige con este imprudente celo en favor de las Declaraciones de Derechos". 6

La objeción básica, por tanto, consistió en que la Constitución pretendía proteger un complejo de derechos individuales mucho más amplio de lo que cualquier documento pudiera enumerar exhaustivamente y que cualquier enumeración explícita de algunos de estos derechos probablemente sería interpretada en el sentido de que los restantes no se hallaban protegidos. La experiencia demostró la existencia de poderosas razones para temer que ninguna declaración de derechos pudiera comprender todos los implicados en los "principios generales que son comunes a nuestras instituciones", 7 y que singularizar algunos de estos derechos parecería entrañar que los otros carecieran de protección.

Por otra parte, pronto se reconoció que la Constitución confería obligatoriamente al gobierno poderes que podrían ser usados para infringir los derechos individuales si tales derechos no fueran especialmente protegidos y que, puesto que algunos habían sido mencionados en el texto constitucional, podía añadirse un catálogo más completo. En este sentido, Madison, en una importante carta a Jefferson, entendió un punto central del debate: ¿del ataque de quién o quiénes se intenta proteger los derechos de los individuos mediante la nueva Constitución?: "Mi opinión ha sido siempre favorable a la declaración de derechos, a condición de que se encuadre de tal forma que no implique poderes que no se desee incluir (...) No es de recelar que la invasión de los derechos privados procede principalmente de actos del gobierno contrarios al sentir de sus constituyentes, sino de actos en los que el gobierno es el mero instrumento de una mayoría de constituyentes. Esta es una verdad de gran importancia a la que no se ha prestado suficiente atención (...) Cabe preguntar: ¿qué utilidad puede contener una declaración de derechos en un gobierno popular? (...) 1. Las verdades políticas declaradas en forma tan solemne adquieren el

\footnotetext{
${ }^{6}$ Idem., $\mathrm{N}^{\mathrm{o}} 84$, p. 368.

${ }^{7}$ John Marshall en el caso Fletcher vs. Peck (1810) citado en Hayek, F., Los Fundamentos de la Libertad,
} Unión Editorial, 1991, p. 231. 
rango de máximas fundamentales del libre gobierno, y como se incorporan al sentimiento nacional, contrarrestan los impulsos del interés y de la pasión". ${ }^{8}$ Bajo una forma popular del gobierno, serían las mayorías las que intentarían controlar el poder del gobierno y en un gobierno que no estuviera limitado, fácilmente podrían pasar por encima de los derechos y libertades de la minoría.

Más tarde se dijo: "Una declaración de derechos es importante y a menudo puede ser indispensable siempre que opere como una calificación de los poderes realmente concedidos por el pueblo al gobierno. Esta es la base real de todas las declaraciones de derechos en la madre patria, en la constitución y leyes coloniales y en las constituciones de los estados (...). La declaración de derechos es una protección importante contra la conducta opresiva e injusta por parte del pueblo mismo". 9 El peligro, tan claramente percibido en su momento, se evitó mediante la cuidadosa previsión en la Novena Enmienda, de que "la enumeración de ciertos derechos en esta Constitución no se interpretará como la negación o menosprecio de otros que conserva el pueblo". ${ }^{10}$

Además, la Constitución emana de "NOSOTROS, EL PUEBLO de los Estados Unidos", y aquí en esta primera frase, dice Publius: "tenemos un reconocimiento de derechos populares superior a varios volúmenes de esos aforismos que constituyen la distinción principal de las declaraciones de derechos de varios de nuestros Estados, y que sonarían mucho mejor en un tratado de ética que en la constitución de un gobierno". ${ }^{11}$

La respuesta institucional de El Federalista respecto del sentido último de la Constitución fue categórica: la Constitución debía delinear cuidadosamente (y por lo tanto delimitar) los poderes del nuevo gobierno, radicándolos en tres poderes que se fiscalizarían y contrapesarían mutuamente. Este arreglo institucional garantizaría que ni el gobierno como un todo ni cualquier parte de él se convierta en algo tan poderoso como para transformarse en una amenaza a los derechos de las personas. Hamilton también creía, junto con Madison, que la república comercial y secular establecida en la nueva Constitución estimularía tal proliferación de intereses económicos y religiosos, que ningún interés o grupo formaría una mayoría permanente al interior de la sociedad. Cuando tal mayoría permanente se aglutinara alrededor de algún interés particular, o creencia religiosa o filosófica en forma radical, se encontrarían frente a una amenaza real a los derechos y libertades de los individuos. ${ }^{12}$ En este escenario, ningún catálogo o lista

${ }^{8}$ Padover, S., The Complete Madison, Padover, 1953, p. 253.

${ }^{9}$ Story, J., Commentaries on the Constitution, Oakshott, 1933, pp. 718 y 720.

${ }^{10}$ La decisión de incluir la novena enmienda en la declaración de derechos es explicada como una consecuencia directa de la vitalidad de los principios que derivan de la constitución "antigua" (inglesa). Muchos comentaristas de la constitución americana concuerdan en que esta enmienda refleja un intento por preservar y reconocer un conjunto indeterminado de derechos naturales (no establecidos en la declaración de derechos). Por ejemplo, para Brest y otros: "Si alguna previsión de la Constitución americana parece englobar el concepto de los derechos naturales, es la novena enmienda”. Brest, P. y otros, Processes of Constitutional Decisionmaking: Cases and Materials, York, 2000, p. 113.

${ }^{11}$ Hamilton, A. y otros, ob. cit., $\mathrm{N}^{\circ} 84$, p. 368.

${ }^{12}$ Idem., $\mathrm{N}^{\text {os }} 9$ y 10. Para muchos autores el $\mathrm{N}^{\circ} 51$ es considerado un resumen, una buena síntesis de toda la obra. 
de derechos o judicatura, por más vigorosa que fuera, podría prevenir por mucho tiempo la opresión de tal mayoría contra los miembros de los grupos de la minoría.

Las limitaciones que se establecerían sobre el gobierno fueron desarrolladas largamente en el más famoso de los documentos de El Federalista. En su $\mathrm{N}^{\circ} 10^{13}$ se establece: "Poner el bien público y los derechos privados a salvo del peligro de una facción semejante y preservar a la vez el espíritu y la forma del gobierno popular, es en tal caso el magno término de nuestras investigaciones”. ${ }^{14}$ Esta afirmación recuerda que la pregunta ¿cómo la Constitución protege los derechos y libertades de los individuos? es esencialmente la misma pregunta respondida en El Federalista: ¿Por qué medios el gobierno será limitado o prevenido de abusar de los poderes que le han sido entregados por necesidad?

Bajo una forma popular, y específicamente en tiempos democráticos, estos poderes serán ejercidos por una mayoría. Como señala Publius, el problema puede ser resuelto solamente, si acaso pudiera serlo, previniendo la formación y por lo tanto la regla de una facción mayoritaria. ${ }^{15}$ Esto puede ser alcanzado mediante determinados arreglos institucionales que en resumen son: "la distribución ordenada del poder en distintos departamentos, la introducción de un sistema de frenos y contrapesos legislativos, la institución de tribunales integrados por jueces que conservarán su cargo mientras observen buena conducta, la representación del pueblo en la legislatura por medio de diputados de su elección (...) y la ampliación de la órbita ${ }^{16}$ en la que esos sistemas han de desenvolverse". ${ }^{17}$

Con todo, en forma posterior, los Federalistas accedieron a incluir una Declaración de Derechos en la Constitución, no por llegar al convencimiento de que esto sería necesario, y por lo tanto debiendo retractarse de la lata argumentación que habían dado contra dicha inclusión, sino que optaron más bien por seguir el camino del pragmatismo político y la prudencia, al darse cuenta que la opinión pública apoyaba en forma mayoritaria la inclusión de una Declaración de Derechos. Este cambio de posición fue defendido por Hamilton señalando que: "una declaración de derechos instituida en la forma apropiada, no sólo traerá seguridad, sino que servirá al doble propósito de satisfacer las mentes de oponentes bien intencionados, y proveerá los resguardos adicionales en favor de la libertad. Bajo este cambio de circunstancias, es mi sincera opinión que la Constitución sea revisada, y que el primer Congreso que se reúna, prepare y recomiende a los Estados ratificar la más satisfactoria de las provisiones para todos los derechos

${ }^{13}$ Un análisis a fondo sobre este ensayo puede encontrarse en Carey, G., "El Federalista", en Revista Estudios Públicos, N ${ }^{\circ}$ 13, Santiago, 1987, y Epstein, D., La Teoría Política de El Federalista, Grupo Editor Latinoamericano, Capítulo III, pp. 87-153.

${ }^{14}$ Hamilton, A. y otros, ob. cit., $\mathrm{N}^{\circ} 10$, p. 38.

${ }^{15}$ Como se sabrá, el centro del ensayo $\mathrm{N}^{\circ} 10$ es analizar las causas y los efectos de la facción y cómo prevenir sus defectos.

${ }^{16} \mathrm{La}$ "ampliación de la órbita" está en el centro del diseño constitucional de la obra dado que se piensa en relación a una República basada en el Federalismo o Federación de Estados.

${ }^{17}$ Hamilton, A. y otros, ob. cit., $\mathrm{N}^{\circ}$ 9, pp. 32-33. 
esenciales, particularmente los derechos de conciencia en sentido amplio, la libertad de prensa, juicios ante tribunales, etc". ${ }^{18}$

\section{Un nuevo Poder Judicial}

El propio Federalista, citando a Montesquieu advierte que "De las tres potestades de que hemos hablado, la de juzgar es en cierto modo nula". ${ }^{19}$ Si para mantener el equilibrio de los poderes públicos -equilibrio frágil que se sustenta en los principios de separación de poderes y en diversos mecanismos institucionales de pesos y contrapesos (checks and balances) - la independencia entre las diferentes ramas del Estado es uno de los requisitos básicos de la estructura legal y política de las sociedades desarrolladas, esto es particularmente cierto en relación al Judicial: "La independencia completa de los tribunales de justicia es particularmente esencial en una Constitución limitada”. ${ }^{20}$

En el $N^{\circ} 78$ Hamilton fundamenta la premisa central sobre la que se fundamenta el nuevo poder judicial: "el (poder) judicial, debido a la naturaleza de sus funciones, será siempre el menos peligroso para los derechos políticos de la Constitución, porque su situación le permitirá estorbarlos o perjudicarlos en menor grado que los otros poderes (...) El judicial (...) no influye ni sobre las armas, ni sobre el tesoro: no dirige la riqueza ni la fuerza de la sociedad, y no puede tomar ninguna resolución activa. Puede decirse con verdad que no posee FUERZA ni VOLUNTAD, sino únicamente discernimiento, y que ha de apoyarse en definitiva en la ayuda del brazo ejecutivo hasta para que tengan eficacia sus fallos (...) Aún cuando en ocasiones sean los tribunales de justicia los que oprimen a los individuos, la libertad general del pueblo no ha de temer amenazas (...) mientras (...) se mantenga realmente aislado tanto de la legislatura como del ejecutivo". ${ }^{21}$

Es por ello que el diseño del Poder Judicial planteado por El Federalista establece diversas instituciones y mecanismos, que tienen por objeto fortalecer la independencia judicial. En primer lugar, será clave contar con un procedimiento especial de nombramiento y destitución, en la que el Senado juega un rol clave: "Respondo que la necesidad de su colaboración (Senado) tendrá un efecto considerable, aunque en general poco visible. Constituirá un excelente freno sobre el posible favoritismo presidencial y tenderá marcadamente a impedir la designación de personas poco adecuadas, debido a prejuicios locales, a relaciones familiares o con miras de popularidad. Por añadidura, sería un factor eficaz de estabilidad en la administración (...) Se comprende fácilmente que un hombre que dispusiera él solo de los empleos públicos se dejaría gobernar por sus intereses e inclinaciones personales con más libertad que estando obligado a someter el

${ }^{18}$ Padover, S., ob. cit., p. 390.

${ }^{19}$ Montesquieu citado en Hamilton, A. y otros, ob. cit., $\mathrm{N}^{\circ} 78$, p. 331 (n. 52). En la versión original, sin embargo, esta frase es aún más lapidaria: "Of the three powers above mentioned, the JUDICIARY is next to nothing". Hamilton, A. y otros, The Federalist Papers, Penguin, 1987, N 78, p. 466.

${ }^{20}$ Hamilton, A. y otros, ob. cit., $\mathrm{N}^{\circ} 78$, p. 331.

${ }^{21}$ Idem., $\mathrm{N}^{\circ} 78$, pp. 330-331. 
acierto de su elección a la discusión y resolución de un cuerpo distinto e independiente, y siendo dicho cuerpo nada menos que toda una rama de la legislatura, la posibilidad de un fracaso serviría de aliciente poderoso para proceder con cuidado al hacer su proposición. El peligro para su reputación y, cuando se trate de un magistrado electivo, para su carrera política, en el caso de que se le descubriera un espíritu de favoritismo o que andaba en forma indebida a caza de popularidad, por parte de un cuerpo cuya opinión tendría gran influencia en la formación de la del público, no puede dejar de obrar como barrera contra ambas cosas. Le daría vergüenza y temor proponer para los cargos más importantes o provechosos a personas sin otro mérito que el de ser oriundas del Estado de que procede, el de estar relacionadas con él de una manera u otra, o el poseer insignificancia y ductilidad necesarias para convertirse en serviles instrumentos de su voluntad". 22

Junto con lo anterior, se consagra como mecanismo de destitución el juicio "político" -acusación constitucional, en otras palabras-. Así los jueces que cometan delitos en el ejercicio de sus funciones: "Pueden ser acusados por mala conducta por la Cámara de Representantes y juzgados por el Senado; si resultan convictos, se les destituirá de su puesto, inhabilitándolos para ocupar cualquier otro. Esta es la única medida sobre el particular que resulta compatible con la independencia que requiere la función judicial y la única que encontramos en nuestra propia Constitución respecto a nuestros jueces". ${ }^{23}$

Asimismo, entre los principios que se incorporaron a la estructura de la Constitución está, señala el $\mathrm{N}^{\circ}$ 9, un poder judicial "integrado por jueces que conservarán sus cargos mientras dure su buena conducta”. ${ }^{24}$ Esta misma fórmula se plantea en el $\mathrm{N}^{\circ} 78$ : "Conforme al plan de la convención, todos los jueces nombrados por los Estados Unidos conservarán sus puestos mientras observen buena conducta, lo cual se halla de acuerdo con las mejores constituciones de los Estados y, entre ellas, con la de este Estado (Nueva York). El hecho de que su utilidad se haya puesto en duda por los adversario del proyecto constituye un grave síntoma de la violenta manía de encontrarlo todo mal, que turba su inteligencia y discernimiento. La regla que hace de la buena conducta la condición para que la magistratura judicial continúe en sus puestos, representa con seguridad uno de los más valiosos progresos modernos en la práctica gubernamental. En una monarquía, crea una excelente barrera contra el despotismo del príncipe; en una república no es menos eficaz contra las usurpaciones y opresiones de la entidad representativa. Y es el mejor instrumento que puede discurrir ningún gobierno para asegurarse la administración serena, recta e imparcial de las leyes". 25

Más aún, el que los tribunales de justicia sean considerados como los baluartes de una Constitución limitada en contra de las usurpaciones legislativas "suministrará un

\footnotetext{
${ }^{22}$ Idem., $\mathrm{N}^{\circ} 76$, pp. 324-25.

${ }^{23}$ Idem., $\mathrm{N}^{\circ} 79$, p. 337.

${ }^{24}$ Idem., $\mathrm{N}^{\circ}$ 9, p. 32.

${ }^{25}$ Idem, $\mathrm{N}^{\circ} 78$, p. 330.
} 
argumento sólido en pro de la tenencia permanente de las funciones judiciales, ya que nada contribuirá tanto como esto a estimular en los jueces ese espíritu independiente que es esencial para el fiel cumplimiento de tan arduo deber". ${ }^{26}$

Además, la buena conducta sería propia del especial método de designación de los jueces: "Esta adhesión uniforme e inflexible a los derechos de la constitución y de los individuos (...) no puede esperarse de jueces que estén en posesión de sus cargos en virtud de designaciones temporales (...) habría el peligro de una complacencia indebida frente al poder que los designa”. ${ }^{27}$

Asimismo, el esquema de remuneraciones sería parte fundamental en la arquitectura organizacional de la nueva judicatura: "Después de la permanencia en el cargo, nada puede contribuir más eficazmente a la independencia de los jueces que el proveer en forma estable a su remuneración (...) Conforme al modo ordinario de ser de la naturaleza humana, un poder sobre la subsistencia de un hombre equivale a un poder sobre su voluntad. En todos los Estados, los partidarios ilustrados del buen gobierno han tenido que lamentar la ausencia de prevenciones precisas y explícitas a este respecto en sus constituciones (...) Consecuencialmente, el proyecto de la convención dispone que los jueces de los Estados Unidos "recibirán a intervalos fijos una remuneración por sus servicios que no podrá ser disminuida durante su permanencia en funciones” (...) Los salarios de los funcionarios judiciales podrán alterarse de tiempo en tiempo, a medida que lo requieran las circunstancias, pero nunca para disminuir los emolumentos a que tiene derecho un juez determinado en la época en que ingresa al servicio". ${ }^{28}$

Por otra parte, sería necesario cautelar las particulares condiciones que necesitarían reunir los miembros de la magistratura. En este sentido señala Hamilton: "Se ha observado a menudo, muy oportunamente, que un voluminoso conjunto de leyes constituye un inconveniente que va necesariamente unido a las ventajas de un gobierno libre. Para evitar una discrecionalidad arbitraria de parte de los tribunales es indispensable que estén sometidos a reglas y precedentes (...) se comprende fácilmente que (...) la compilación de dichos precedentes crecerá inevitablemente hasta alcanzar un volumen considerable, y que para conocerlos adecuadamente será preciso un estudio laborioso y dilatado. Por esta razón serán pocos los hombres en cada sociedad suficientemente versados en materia de leyes para estar capacitados para las funciones judiciales. Y si descontamos lo que corresponde a la perversidad natural del género humano, han de ser menos aún los que unan a los conocimientos requeridos la integridad que debe exigirse". ${ }^{29}$

Finalmente, para el propio Madison, resultaba crucial el rol que respecto de la defensa de la Constitución, y los derechos y libertades garantizados en ella, le cabría al poder judicial: "Una vez que la Declaración de Derechos fuera incorporada a la Constitución, los Tribunales de justicia independientes se considerarían a sí mismos los guardianes de

\footnotetext{
${ }^{26}$ Idem., $\mathrm{N}^{\mathrm{o}} 78$, p. 333.

27 Idem., $\mathrm{N}^{\mathrm{o}} 78$, p. 335.

${ }^{28}$ Idem., $\mathrm{N}^{\mathrm{o}} 79$, p. 337.

${ }^{29}$ Idem., $\mathrm{N}^{\mathrm{o}} 78$, p. 335.
} 
dichos derechos. Las cortes se transformarían en un bastión impenetrable contra cualquier abuso por parte de alguna de las otras ramas del Estado Federal, legislativo y ejecutivo, y sería llevado naturalmente a resistir cada usurpación sobre los derechos estipulados expresamente en la constitución por dicha Declaración de Derechos". ${ }^{30}$

El fundamento de existencia y efectividad de la tutela de la Constitución por parte del Poder Judicial es la necesaria autonomía que debe poseer éste respecto de los otros poderes del Estado, y así lo entendieron los Federalistas. El poder judicial federal fue establecido independiente de las otras ramas del gobierno en orden a que los jueces pudieran de mejor manera ser capaces de "realizar su labor como fieles guardianes de la Constitución"; 31 en este sentido, debían ser capaces de hacer cumplir los límites que establecía la Constitución a las otras ramas del Estado y especialmente respecto de aquella que los padres fundadores pensaban que podría convertirse en la mayor amenaza: el legislativo. Actuando bajo este mandato, ellos representarían al resto de los ciudadanos de los Estados Unidos en su capacidad soberana o constituyente; o, expresado de otra manera, el ejercicio del poder que detentan pertenecía por derecho natural a las personas, quienes escribieron y ratificaron la Constitución, y que además tienen el poder para reformarla. ${ }^{32}$

Sin embargo, para los autores de El Federalista, el poder para hacer cumplir la Constitución por cualquier medio "no supone de ningún modo la superioridad del poder judicial sobre el legislativo. Sólo significa que el poder del pueblo es superior a ambos y que donde la voluntad de la legislatura, declarada en sus leyes, se halla en oposición con la del pueblo, declarada en la Constitución, los jueces deberán gobernarse por la última de preferencia a la primera". ${ }^{33}$ Además, sostiene Publius: "Mientras el pueblo no haya anulado o cambiado la forma establecida, por medio de un acto solemne y legalmente autorizado, seguirá obligándolo tanto individual como colectivamente; y ninguna suposición con respecto a sus sentimientos, ni aún el conocimiento fehaciente de ellos, puede autorizar a sus representantes para apartarse de dicha forma previamente al acto que indicamos". 34

Si los representantes de la gente en su capacidad legislativa están sujetos a tales límites, parece evidente por sí mismo que los representantes de la soberanía del pueblo, esto es, los jueces, están sujetos a los mismos límites estrictos. Los jueces son independientes, pero deben dicha independencia al criterio de los padres fundadores quienes vieron que sólo con ésta podrían ejercer en forma efectiva el poder que por derecho

${ }^{30}$ Padover, S., ob. cit., p. 344.

${ }^{31}$ Hamilton, A. y otros, ob. cit., $\mathrm{N}^{\circ} 78$, p. 334.

32 Este poder, sin embargo, es ejercido por el poder judicial y no por las mismas personas por las razones dadas por Publius en El Federalista $\mathrm{N}^{\circ}$ 49, lo cual es consistente con toda la teoría del rol del Estado en la sociedad que impulsa el liberalismo clásico, desarrollada por Adam Smith en su Investigación sobre la naturaleza y causas de la riqueza de las naciones, Fondo de Cultura Económica, 1958, pp. 612-613, y que ha sido revisado y reafirmado por Milton Friedman en Libertad de Elegir, Orbis, Madrid, 1983, pp. 48-56.

${ }^{33}$ Hamilton, A. y otros, ob. cit., $\mathrm{N}^{\circ} 78$, p. 332.

${ }^{34}$ Idem., $\mathrm{N}^{\circ} 78$, p. 333. 
natural corresponde a otra persona, el pueblo constituyente. Al pueblo le pertenece el poder de ordenar y establecer la Constitución con sus derechos específicos, y sólo a ellos, al pueblo en su capacidad soberana, pertenece el poder de reformar la Constitución y sumar o quitar los derechos establecidos. Los padres fundadores se habrían opuesto rotundamente al hecho de dotar a los jueces del poder y autoridad para "crear" derechos y habrían calificado como una usurpación el ejercicio de tal poder sin la autorización correspondiente.

Asimismo, un poder judicial fuerte e independiente, según Hamilton, sería pieza fundamental en orden a proteger la Constitución y los derechos individuales: "de los efectos de esos malos humores que las artes de hombres intrigantes o la influencia de coyunturas especiales esparcen a veces entre el pueblo, y que (...) tienen (...) la tendencia a ocasionar peligrosas innovaciones en el gobierno y graves opresiones del partido minoritario (...) es fácil comprender que se necesitaría una firmeza poco común de parte de los jueces para que sigan cumpliendo con su deber como fieles guardianes de la Constitución, cuando las contravenciones a ella por el legislativo hayan sido alentadas por la opinión de la mayor parte de la comunidad". ${ }^{35}$ Pero no es sólo en el caso de las infracciones a la Constitución como la independencia de los jueces puede constituir una salvaguardia esencial contra los efectos de "esos malos humores" circunstanciales que suelen penetrar a la sociedad, porque como señala Hamilton: "En ocasiones, éstos no van más allá de perjudicar en sus derechos privados a una clase determinada de ciudadanos, por medio de leyes injustas y parciales. Aquí también reviste gran importancia la firmeza de la magistratura mitigar la severidad y limitar el efecto de esa clase de leyes. No sólo sirve para moderar los daños inmediatos de las ya promulgadas, sino que actúa como freno del cuerpo legislativo para aprobar otras, pues percibiendo éste los obstáculos al éxito de sus inicuos designios que son de esperarse de los escrúpulos de los tribunales, se verá obligado a modificar sus intentos debido a los móviles mismos de la injusticia que medita realizar (...) Los hombres prudentes, de todas las condiciones, deben apreciar en su verdadero valor todo lo que tienda a inspirar y fortalecer ese temple en los tribunales, ya que nadie tiene la seguridad de no ser víctima de móviles injustos el día de mañana, no obstante que hoy se beneficie de ellos". ${ }^{36}$

Será paradójicamente un francés, De Tocqueville, quien mejor resumirá la importancia decisiva del nuevo papel constitucional que el sistema judicial había pasado a tener en el funcionamiento de la democracia americana, y que se basaría en los principios establecidos por El Federalista: una democracia a cuya preservación concurrían, según él, no sólo la forma federal y las instituciones municipales, moderadoras, una y otras, del "despotismo de la mayoría", sino también el poder judicial: "La tercera (cosa que sirve al mantenimiento de las instituciones políticas de los americanos) se encuentra en la constitución del poder judicial. He mostrado cómo los tribunales sirven para corregir los extravíos de la democracia y cómo, sin poder detener nunca los movimientos de la

\footnotetext{
${ }^{35}$ Idem., $\mathrm{N}^{\mathrm{o}} 78$, p. 333.

${ }^{36}$ Idem., $\mathrm{N}^{\circ} 78$, p. 334.
} 
mayoría, consiguen frenarlos y dirigirlos", ${ }^{37}$ texto en el que, tras destacar el profundo contraste existente en ese ámbito entre América y Europa, había convertido en Estados Unidos al poder judicial "en la parte más nueva y original de todo el sistema político". ${ }^{38}$ La peculiaridad fundamental de la función que se había reservado a la magistratura del otro lado del Atlántico consistía en que: "Los americanos han establecido el poder judicial como contrapeso y barrera al poder legislativo; lo han hecho un poder político de primer orden (...) El juez americano se parece, por tanto, perfectamente a los magistrados de otras naciones. Sin embargo, está revestido de un inmenso poder político que estos no tienen. Su poder forma la más terrible barrera contra los excesos de la legislatura". Una barrera que, a juicio de De Tocqueville, no era otra que la derivada de la posibilidad de juzgar sobre la constitucionalidad de las normas aprobadas por el poder legislativo. Este liberal francés va a explicarlo, otra vez, con sencillez y concisión: "La causa está en este solo hecho: los americanos han reconocido a los jueces el derecho a fundamentar sus decisiones sobre la Constitución más que en las leyes. En otros términos, le han permitido no aplicar las leyes que les parezcan inconstitucionales". ${ }^{39}$ El cómo se había llegado a conceder un papel tan relevante -entregar tal poder político al Judicial en la formulación de De Tocqueville-, será objeto del análisis que se presenta a continuación.

\section{CONTROL DE LA CONSTITUCIONALIDAD ${ }^{40}$}

Entre los principios e instituciones que sostienen la teoría constitucional de $E l$ Federalista, un rol mayor le tocaría cumplir al Poder Judicial, como hemos visto en el apartado anterior; y no tan sólo en cuanto a la necesidad de independencia para cumplir con sus funciones propias. Dentro de estos principios e instituciones elaborados por $E l$ Federalista la separación de poderes, por ejemplo, impediría la tiranía que importa la

${ }^{37}$ De Tocqueville, A., La democracia en América, Madrid, 1984, p. 278.

${ }^{38}$ La cita completa es la siguiente: "Varios estados de Europa han adoptado el sistema representativo, pero no creo que hasta el presente ninguna nación del mundo haya constituido el poder judicial de la misma manera que los americanos. La constitución del poder judicial forma, en mi opinión, la parte más nueva y original de todo el sistema político de los americanos”. Idem., pp. 100-101.

${ }^{39}$ De Tocqueville no deja de notar, en todo caso, los límites dentro de los cuales ejercerían los jueces norteamericanos sus facultades de control, límites que entroncan con lo que hoy denominaríamos el carácter incidental del juicio de constitucionalidad: "Si el juez hubiese podido atacar las leyes de una manera teórica y general, si hubiese podido tomar la iniciativa y censurar al legislador, hubiese entrado estrepitosamente en la escena política. Convertido en el campeón o adversario de un partido, hubiese llamado a tomar parte en la lucha a todas las pasiones que dividen el país. Pero cuando el juez ataca la ley en un debate oscuro y en una aplicación particular, oculta en parte a las miradas del público la importancia del ataque. Su sentencia únicamente tiene por objeto afectar a un interés individual, la ley sólo es herida por casualidad". Idem., p. 105.

${ }^{40}$ Un desarrollo más extenso de este punto se puede encontrar en García, J.F., "El control de constitucionalidad en El Federalista y los fundamentos de una sociedad libre", en Revista Chilena de Derecho $\mathrm{N}^{\circ}$ 30, Vol. 3, 2003. 
concentración de todas las funciones gubernamentales, que permite que uno, pocos o muchos gobiernen en forma arbitraria. Así, entonces, el gobierno queda "limitado".

Pero Publius también cree que la Constitución es la ley fundamental, que las instituciones que crea -legislatura, ejecutivo y judicial- están obligadas a obedecer. Haciendo una diferencia entre las Constituciones británica y la americana señala: "La distinción importante también entendida en Estados Unidos entre una Constitución establecida por el pueblo e inalterable por el gobierno, parece haber sido poco comprendida y aún menos observada en cualquier otro país. Dondequiera que haya residido el poder supremo del legislativo, allí también se ha supuesto que reside el poder pleno para cambiar aquella forma de gobierno. Incluso en Gran Bretaña, donde los principios de la libertad política y civil han sido analizados muy ampliamente y donde conocemos la mayoría de los derechos de la Constitución, se mantiene que la autoridad del parlamento es trascendente e incontrolable tanto con respecto a la Constitución como con respecto a los objetos ordinarios de las cláusulas legislativas". ${ }^{41}$

Sin embargo, esto no sucede, asegura, bajo la Constitución de los Estados Unidos, puesto que todas las ramas del gobierno, incluyendo el legislativo, están obligadas por la Constitución. Hay dos aspectos un tanto distintos del pensamiento de Publius respecto a la idea de gobierno limitado. El primero se relaciona a cómo o por qué medios se harán cumplir aquellas limitaciones establecidas en la Constitución; el segundo, a la naturaleza, carácter y especie de las limitaciones que la Constitución, en cuanto ley básica o fundamental, debería contener. Respecto a este último aspecto, se puede señalar que Publius es bastante categórico en su argumentación de que la sola inclusión de un Bill of Rights no es garantía suficiente y, por el contrario, la respuesta de El Federalista va orientada en la línea de la configuración de poderes públicos limitados por parte de la Constitución.

Con todo, no existe duda respecto a las enseñanzas de Publius respecto al primero de estos asuntos. Dice en El Federalista No 78 que "una Constitución limitada" -que, en el contexto de un gobierno republicano, significa una en la cual existen limitaciones específicas y expresas a la autoridad legislativa- puede mantenerse en la práctica sólo mediante los tribunales de justicia, cuyo deber debe ser declarar nulos todos aquellos actos contrarios al tenor manifiesto de la Constitución.

En este sentido, si se considera que el principal objetivo de la Constitución americana fue establecer límites a la actuación del gobierno, particularmente a la legislatura, se hace evidente que debían adoptarse medidas para aplicar tales restricciones según los métodos fijados en relación con otras leyes y principalmente a través de tribunales. No es sorprendente, por tanto, el que un cuidadoso historiador encuentre que "la revisión judicial, en vez de ser una invención americana, es tan vieja como el derecho constitucional mismo y sin ella nunca hubiera quedado implantado el constitucionalismo”. ${ }^{2}$

${ }^{41}$ Hamilton, A. y otros, ob. cit., $\mathrm{N}^{\mathrm{o}} 78$, p. 331.

${ }^{42}$ McIllwain, C., Constitucionalismo antiguo y moderno, Centro de Estudios Constitucionales, 1991, p. 278. Para una discusión respecto de si acaso la revisión judicial puede ser cuestionada bajo estándares democráticos ver Ackerman, B., We the people (1): Foundations, Harvard University Press, 1991, y "Constitutional Politics/ 
En razón del carácter del movimiento que condujo a la redacción de una Constitución codificada, debe ciertamente parecer curioso que no se haya discutido jamás la necesidad de tribunales que puedan declarar la constitucionalidad de las leyes. El hecho importante, en definitiva, es que para algunos redactores de la Constitución la revisión judicial era una parte necesaria y per se evidente del texto en cuestión; que cuando se presentó la ocasión de defender la concepción en las primeras discusiones, tras haber sido adoptados aquellos redactores, fueron suficientemente explícitos. La frase más famosa es encontrada en El Federalista $\mathrm{N}^{\circ} 78$ : "Siempre que un estatuto particular se halla en contraposición de la Constitución, es deber de los tribunales judiciales adherirse a esta última y repudiar el primero". 43

La idea de jurisdicción constitucional está vinculada íntimamente con la intención de velar en forma efectiva por la supremacía constitucional y de solucionar, aplicando criterios jurídicos, los conflictos constitucionales que surjan entre los órganos estatales supremos. Nada se saca con dictar una Constitución que no se aplica o cuya normativa no se visualice como obligatoria para todos los habitantes de un Estado y, especialmente, para aquellos que gobiernan. En este punto, parece relevante señalar que ya en 1610 existía un precedente en este ámbito, cuando el juez Sir Edward Coke, con motivo del Bonham's Case señaló: "Aparece en nuestros libros que en muchos casos, el common law controla las leyes del parlamento y a veces decide que son enteramente nulas; porque cuando una ley aprobada por el parlamento es contraria a común derecho y razón, o repugnante, o de imposible ejecución, el common law debe dominar sobre ella y pronunciar la nulidad de tal ley". ${ }^{44}$ Esta opinión constituye una de las primeras manifestaciones del pensamiento moderno en torno al principio de control constitucional y más exactamente al judicial review of legislation, demostrando la profunda raigambre inglesa del sistema de control constitucional norteamericano. ${ }^{45}$

Constitutional Law", 99 Yale Law Journal 3, 1989; Dahl, R., "Decision-Making in a Democracy: The Role of the Supreme Court as a National Policy-Maker”, 6 Journal of Public Law 279, 1957; Kramer, L., The People Themselves: Popular Constitutionalism and Judicial Review, Oxford University Press, 2004; Rosenberg, G., "Judicial Independence and the Reality of Political Power", 54 Review of Politics 369, 1992; Sunstein, C. y otros, "Ideological Voting on Federal Courts of Appeals: A Preliminary Investigation", 90 Virginia Law Review 301, 2004; y McCloskey, R., The American Supreme Court, University of Chicago Press, 2005

${ }^{43}$ Hamilton, A. y otros, ob. cit., $\mathrm{N}^{\circ} 78$, p. 333.

${ }^{44}$ Baker, J., An Introduction to English Legal History, Butterworths, 1979, p. 182.

${ }^{45}$ Con todo, no todos los autores están de acuerdo en esta tesis. En este sentido, Kramer sostiene: "Una última característica parece relevante para entender la Constitución consuetudinaria (inglesa), y es que ésta no contiene nada parecido a lo que actualmente entendemos por revisión judicial. Esto no se debe a que la interpretación y aplicación constitucional estén reservadas al Parlamento. La doctrina de la supremacía legislativa comienza a ganar adeptos sólo en la segunda década del siglo XVIII, después de la aprobación del Septentional Act de 1716 (...) Había una época en que era popular leer la opinión de Sir Edward Coke en relación al caso Bonham (...) Como señala J. Pocock, 'el fantasma de la revisión judicial' en la jurisprudencia de Coke fue mandada al olvido por J. W. Gough en 1955. El acierto de Gough fue poner las sentencias de Coke en su real contexto, contexto basado en el acercamiento de Coke a las posturas del Parlamento en su oposición a las extravagantes solicitudes de Jacobo I para aumentar las prerrogativas reales. Los esfuerzos de Coke no apuntaban al establecimiento de un control judicial sobre la ley fundamental, sino a limitar los poderes del rey vis a vis del Parlamento. (...) Coke simplemente proponía una regla de interpretación estatutaria, acorde 
Así las cosas, antes de que se pronunciara la famosa sentencia del Presidente de la Corte Suprema americana John Marshall, en 1803 en el caso Marbury v. Madison, en que se declaraba inconstitucional una ley federal, los autores de El Federalista habían delineado en forma casi perfecta un modelo de obligatoriedad de la declaración judicial de inaplicabilidad de las leyes federales que fueran contrarias a las previsiones de la Constitución. ${ }^{46}$ Tal esquema iba a sostenerse, esencialmente, en la idea de que la Carta Fundamental no era una simple ley, sino una norma cualitativamente diferente, lo que además venía claramente demostrado en su artículo $\mathrm{V}$ que disponía un procedimiento especial para introducir reformas a esta. ${ }^{47}$

La rigidez constitucional y, esencialmente, el carácter expreso de la reforma constitucional van a tener, efectivamente, una decisiva importancia en Estados Unidos, donde la reforma será operativa más como idea sustentadora de la superioridad de la Constitución sobre la ley que como institución efectiva para la adaptación histórica de aquélla. Es innegable, ciertamente, que cuando los comentaristas de la Constitución se

a la cual una ley que contradijera principios legales establecidos sería apartada en ausencia de una clara regla en contrario (...) Así, no se puede caer en el error de interpretar las intenciones de Coke como un deliberado esfuerzo en establecer ni siquiera un modesto precedente o sistema de revisión judicial, porque ninguno de los escritos de este autor hace presumir su concepción de la ley fundamental en esos términos”. Kramer, L., "Foreword: We the Court", en Harvard Law Review, N ${ }^{\circ} 115,2001$, p. 25.

${ }^{46}$ Resulta interesante señalar que El Federalista $\mathrm{N}^{\circ} 78$, y sus argumentos a favor de la revisión judicial, no tuvo ninguna influencia en la ratificación de la Constitución, a nivel federal. Se debe recordar que $E l$ Federalista se escribe con la intención de apoyar la ratificación de la Constitución Federal, pero centrada en Nueva York. Esto se debe a que "nadie vio este ensayo, como tampoco los argumentos de Brutus (pseudónimo equivalente a Publius de los Antifederalistas), durante la campaña de ratificación. Brutus era valorado en un pequeño círculo de intelectuales, pero su obra no había sido propiamente "popularizada" o leída. Por su parte, la audiencia de Publius era inmensamente mayor, sin embargo, su status de obra trascendente se entiende como un fenómeno postratificación (...) Esto es particularmente cierto respecto del $\mathrm{N}^{\circ} 78$, que no fue incluido en la serie original de periódicos y vio por primera vez la luz sólo en la segunda publicación de la obra "El Federalista" a fines de mayo de 1788, demasiado tarde para influenciar cualquier convención de ratificación excepto la de New York”. Craine, E., Publius in the Provinces: Where Was The Federalist Reprinted Outside New York City?, Wm \& Mary Q., 1964, p. 589.

Con todo, y a pesar de que la revisión judicial no fue tocada en profundidad en el período de ratificación (salvo por Publius en el $\mathrm{N}^{\circ} 78$ y por algunos ensayos de Brutus), se puede encontrar una presentación bastante completa en J. Wilson, quien aparentemente fue persuadido para aceptar una versión más amplia de la revisión judicial a aquella defendida en la Convención Federal. En una de sus intervenciones menos felices en la Convención de Ratificación de Pennsylvania, señalo: "Yo digo, bajo esta Constitución, que la legislatura puede ser restringida, y mantenida dentro de las fronteras establecidas, por la actuación del departamento judicial. Espero, señor, explicar esto en forma clara y satisfactoria. Tuve la ocasión cierto día (...) de señalar que el poder de la Constitución era superior al poder de la legislatura, y que actuando en esa capacidad, puede traspasar los límites permitidos, y el acto puede pasar, en el modo usual, sin siquiera notarlo; pero cuando sea el caso de que llegue a conocimiento y discusión por los jueces, y considerando los principios consagrados en ella, la consideren (la ley) incompatible con el poder superior de la Constitución, es su deber pronunciarse por su nulidad".

${ }^{47}$ En esta materia, muchos de los razonamientos y argumentos esgrimidos pueden encontrarse también en Blanco, R., El valor de la Constitución. Separación de poderes, supremacía de la ley y control de constitucionalidad en los orígenes del Estado Liberal, Alianza Editorial, 1994, pp. 118-135. También ver Ketcham, R., Escritos Antifederalistas y Debates de la Convención Constitucional de Estados Unidos, Hacer, 1996. 
ocupan en El Federalista expresamente de la cuestión de la reforma, no van a conectarla con la de la superioridad de la Constitución sobre la ley.

Será en el $\mathrm{N}^{\circ} 78$ de El Federalista en el que Hamilton se explayará respecto de la funcionalidad constitucional del poder judicial como garante último de la supremacía de la Constitución, en el que los autores del comentario abordarán expresamente la vinculación que no podía sino existir entre la mencionada superioridad y el carácter expreso de la reforma constitucional: "Aunque confío en que los partidarios de la Constitución que ha sido propuesta no estarán nunca de acuerdo con sus adversarios en poner en duda el principio fundamental del gobierno republicano que admite el derecho del pueblo a modificar o abolir la Constitución establecida en cualquier momento en que lo considere contradictorio con su felicidad, no debe inferirse de tal principio que los representantes del pueblo puedan violar justificadamente algunas de las previsiones de la Constitución, en cualquier momento en que una mayoría de sus electores de forma momentánea considerasen sus inclinaciones incompatibles con la Constitución existente; o que los tribunales deban considerarse en la obligación de aceptar las infracciones cometidas por tal causa, de la misma forma que no lo estarían si las mismas procedieran de las intrigas del cuerpo representativo. Hasta que el pueblo por medio de alguna ley solemne y competente, haya anulado o cambiado la forma de gobierno establecida, estará vinculado a la misma, tanto colectivamente, como desde el punto de vista individual; y ninguna presunción, ni incluso ningún conocimiento de los sentimientos del pueblo, puede justificar a sus representantes para apartarse de la Constitución, antes de haber aprobado tal ley". 48

¿Cuál era la forma para garantizar el respeto irrestricto a una ley que sólo de forma expresa podía ser modificada? La respuesta de Hamilton sería simple: "Las limitaciones de esta clase (al legislativo) no pueden preservarse en la práctica por otra vía que la de los tribunales de justicia, cuyo deber será declarar nulas todas las leyes contrarias al sentido manifiesto de la Constitución. Sin ello todas las reservas que se realicen respecto a determinados derechos o privilegios serían letra muerta". ${ }^{49}$ La argumentación de Publius se basa por una parte en la peligrosidad del legislativo y, por la otra, en la particular inocuidad del judicial, ${ }^{50}$ lo que hacían de este último un garante completamente idóneo del ejercicio de sus facultades por parte del primero y le permiten llevar a cabo no sólo una protección jurídica del texto de la Constitución, sino también una política, de su espíritu, pues la Constitución es también un ámbito de garantías de los derechos de los particulares y, muy especialmente, de aquellos que están en posición minoritaria.

La intervención de los jueces, en definitiva, resulta fundamental para conservar no tan sólo la integridad jurídica de la Constitución, sino su espíritu, y, por lo tanto, conser-

\footnotetext{
${ }^{48}$ Hamilton, A. y otros, $\mathrm{N}^{\circ} 78$, pp. 333-334.

${ }^{49}$ Idem., $\mathrm{N}^{\circ} 78$, p. 331.
}

${ }^{50}$ En este sentido, "Cualquiera que considere atentamente los distintos órganos del poder podrá percibir que, en un gobierno en que se encuentran separados unos de otros, el judicial, por la propia naturaleza de sus funciones, será siempre el menos peligroso para los derechos políticos de la Constitución, porque él tendrá una capacidad muy inferior para molestarlos o perjudicarlos”. Idem., No 78, p. 331. 
vándola, evitar las "graves opresiones sobre el partido minoritario en la Comunidad". 51 Consciente Hamilton de los efectos que en términos de legitimidad podría traer la intervención judicial al defender la Constitución, explicará por qué la función de control de la constitucionalidad era un derecho (y una obligación jurídica) que, en un sistema de gobierno limitado, correspondía al poder judicial por la propia naturaleza de las funciones que tal poder tenía encomendadas.

En este sentido, Hamilton abordará en forma previa una cuestión conexa de gran importancia: la de si esa facultad judicial de controlar al órgano legislativo del Estado convertía de hecho a la magistratura en superior de la legislatura, ${ }^{52}$ discusión decisiva en la evolución del debate sobre la legitimidad de la revisión judicial de la legislación: "Se argumenta que una autoridad que puede declarar nulos los actos de otra debe ser necesariamente superior a aquella cuyos actos han sido declarados nulos. Como esta doctrina tiene una gran importancia en todas las Constituciones americanas, será conveniente una breve discusión sobre las bases en que se asienta". ${ }^{53}$ Lo anterior servirá a Publius como fundamento de su argumentación en el sentido de que la magistratura no puede, en el ejercicio de su función natural, la de interpretar y aplicar normas jurídicas, eludir su obligación de declarar nulas las leyes contrarias a la Constitución, en la medida en que esa nulidad resulta sólo una consecuencia, asimismo natural, de los principios que rigen en cualquier sistema constitucional, es decir, en cualquier sistema presidido por una ley fundamental. Según él, afirmar, como hacían los detractores de la judicial review of legislation, que al declarar nula una ley contraria a la Constitución los jueces estaban inmiscuyéndose en el ámbito del poder legislativo, sería tanto como negar la posibilidad de que los jueces existiesen como órganos separados del legislativo. $\mathrm{Y}$ es que los jueces no sólo ejercen en esos supuestos un derecho, sino que dan curso a una obligación que emana del concepto de gobierno limitado: el de garantizar y hacer respetar la superioridad formal de la Constitución sobre la ley.

En este sentido, la supremacía formal de la Carta Fundamental es el principio jurídico esencial sobre el cual descansan los argumentos de El Federalista $\mathrm{N}^{\circ}$ 78: la Constitución no es simplemente una ley más dentro del conjunto de leyes que forman parte del ordenamiento jurídico, sino que es la norma más importante y fundamental sobre la cual descansan el resto de las leyes. Esta característica, la supremacía formal de la Constitución, refleja tanto la intención del poder constituyente, representativo de la sociedad civil (el pacto social en la visión lockeana) por establecer una necesaria correlación racional en el orden y jerarquía de las fuentes, como asimismo la supremacía material de la Constitución, puesto que es en este principio donde se contienen los fundamentos del orden social imperante en todas sus dimensiones: económicas, sociales, políticas y especialmente doctrinarias. Consecuencia evidente de la supremacía consti-

${ }^{51}$ Idem., $\mathrm{N}^{\mathrm{o}} 78$, p. 331.

52 "Se han suscitado dudas respecto del poder de los tribunales de declarar nulos los actos del legislativo basándose en que son contrarios a la Constitución, como consecuencia de la idea errónea de que esa doctrina implicaría la superioridad del poder judicial sobre el legislativo”. Idem., No 78, p. 332 .

53 Idem. 
tucional, tanto formal como asimismo material, es que todas las normas jurídicas cuya vigencia se disponga han de conformarse sustancial y formalmente a ella y que, por lo tanto, carecen de todo valor si pugnan con la Carta. Hamilton también se hará cargo de esta controversia: "No hay proposición que dependa de principios más claros que la que afirma que todo acto de una autoridad delegada, contrario al tenor del mandato bajo el cual se ejerce, es nulo. Por tanto, ninguna ley contraria a la Constitución puede ser válida. Negar esto sería tanto como afirmar que el diputado es superior al mandante; que el siervo es superior al amo; que los representantes del pueblo son superiores al propio pueblo; y que los hombres que actúan en virtud de apoderamiento pueden hacer no sólo lo que éste no permite, sino incluso lo que prohíbe". 54

Con todo, Hamilton procederá a enunciar el argumento central de su razonamiento: el de las consecuencias que los jueces deberían obtener, en el ejercicio de su función aplicadora del derecho, de la evidencia que el propio Hamilton acababa de sentar: "No es admisible la suposición de que la Constitución haya tenido la intención de facultar a los representantes del pueblo para sustituir su voluntad por la de sus constituyentes. Es más racional suponer que los tribunales han sido concebidos como un cuerpo intermedio entre el pueblo y la legislatura, con la finalidad, entre otras, de mantener a aquélla dentro de los límites asignados a su autoridad. La interpretación de las leyes es propia y peculiarmente de la incumbencia de los tribunales. Una Constitución es de hecho una ley fundamental y así debe ser considerada por los jueces. A ellos pertenece, por lo tanto, determinar su significado, así como el de cualquier ley que provenga del cuerpo legislativo. Y si ocurriere que entre las dos hay una discrepancia, debe preferirse, como es natural, aquella que posee fuerza obligatoria y validez superiores; en otras palabras, debe preferirse la Constitución a la ley ordinaria, la intención del pueblo a la intención de sus mandatarios". 55

Por lo tanto, la superioridad formal de la Constitución sobre la ley y la consecuente obligación para los jueces de aplicar el ordenamiento sobre ese principio constitucional (por fundador) fundamental, no es más que una derivación ineludible de su superioridad formal, del hecho de que la Constitución, a diferencia de la ley, procede del poder constituyente del Estado y del correlativo de que por proceder de ese poder superior a todos los demás, no puede ser sino modificada de forma expresa a través de una ley solemne y competente a tal efecto. ${ }^{56}$ Hamilton lo subraya, cerrando su reflexión sobre la funcionalidad del poder judicial en el Estado constitucional: "Esta conclusión no significa en modo alguno la superioridad del poder judicial sobre el legislativo. Sólo supone que el poder del pueblo es superior a ambos, y que donde la voluntad de la legislatura, declarada en las leyes, entra en contradicción con la del pueblo, declarada en la Constitución, los jueces deberán conformarse a la última de las preferencias y no a las primeras. Deberán regular sus decisiones por las leyes fundamentales y no por las que no tienen este carácter fundamental”.

\footnotetext{
${ }^{54}$ Idem.

${ }^{55}$ Idem.

${ }^{56}$ Idem.
} 
La cuestión que parece surgir en forma natural es la de si existía en la Constitución de 1787 alguna base jurídica en la que sostener una atribución tan trascendental a la magistratura. En esta materia, Publius ya en el $\mathrm{N}^{\circ} 78$ de El Federalista había dedicado un comentario tangencial de su forma de enfrentarse a esta cuestión. ${ }^{57}$ Según Hamilton, aunque la Constitución no admitía expresamente la revisión judicial de la legislación, tampoco la prohibía expresamente, de lo que debería deducirse que la misma quedaba contemplada en el sistema constitucional americano, pues esa intervención limitadora de los jueces resultaba ser un elemento indispensable de una Constitución limitada. En este sentido, y tras admitir Hamilton que "no existe una sílaba en el plan que se presenta a nuestra consideración que directamente faculte a los tribunales nacionales para interpretar las leyes de acuerdo con el espíritu de la Constitución”, Hamilton explicaba por qué tal facultad debía admitirse en la Constitución de modo implícito, toda vez que la misma no la había prohibido expresamente: “Admito, sin embargo, que la Constitución deberá ser el canon para la interpretación de las leyes y que siempre que se plantee una contradicción evidente, las leyes deben ceder ante la Constitución. Pero esta doctrina no es deducible de ninguna circunstancia peculiar del plan de la convención, si no de la teoría general de una Constitución limitada; y hasta donde sea cierta es igualmente aplicable a la mayoría, sino a todos los gobiernos de los estados. No puede fundarse en esta circunstancia ninguna objeción, por tanto, contra la judicatura federal que no fuera también en contra de las judicaturas locales, y que no sirva para condenar a cualquier Constitución que pretenda poner límites a la discrecionalidad del poder legislativo". 58

La gran contribución de El Federalista en materia de revisión judicial es, sin lugar a dudas, el haber sembrado de alguna manera las semillas suficientes para que brotara una mentalidad constitucional, que se había ido asentando poco a poco en los territorios de la Unión y que acabará muy pronto dando un fruto de significación histórica extraordinaria. En efecto, cuando el juez John Marshall dicte su sentencia en el caso de Marbury vs. Madison se verá reproducido en una resolución judicial, que declara inaplicable por inconstitucional una ley federal, una buena parte de los razonamientos previamente expuestos por Hamilton y El Federalista.

\section{CONCLUSIONES}

El proyecto constitucional de El Federalista de cómo diseñar una carta fundamental que tuviera como horizonte, tanto teórico como práctico, el garantizar los derechos y libertades de las personas, se centraba ante todo en la configuración de poderes públicos limitados a través de los cuales se imponían las necesarias restricciones a quienes mayor

57 "Si se dijera que el cuerpo legislativo es por sí solo constitucionalmente el juez de sus propios poderes y que la interpretación que se haga de ellos es concluyente para los otros órganos, se podría responder que ésta no puede ser la presunción natural en los casos en que no se derive de alguna particular previsión de la Constitución”. Idem.

${ }^{58}$ Hamilton, A. y otros, $\mathrm{N}^{\circ} 81$, p. 344. 
daño podrían causar en una república que asumía la forma representativa: las mayorías que se formaran al interior del poder legislativo. Así, la esencia de la Constitución radicaba en delinear cuidadosamente (y por lo tanto delimitar) los poderes del nuevo gobierno, radicándolos en tres poderes que se fiscalizan y contrapesan mutuamente. Este arreglo institucional ayuda a garantizar que ni el gobierno como un todo ni cualquier parte de él se convierta en tan poderoso como para pasar a ser una amenaza a los derechos de las personas.

En este diseño el rol del Poder Judicial sería fundamental. Su especial naturaleza y su posición relativa en comparación a los poderes políticos la hacen idónea para cumplir con el principal desafío impuesto por los padres fundadores: garantizar la supremacía constitucional, garantizando de paso los derechos y libertades de los individuos, especialmente los de las minorías, cualesquiera que ellas fueran. Como hemos visto, pieza fundamental en este diseño institucional sería el control de la constitucionalidad de la legislación, lo que convierte -y terminó convirtiendo tras doscientos años de ejercicio- al Poder Judicial americano en uno de los más poderosos del mundo.

\section{BIBLIOGRAFÍA}

Ackerman, B., We the people (1): Foundations, Harvard University Press, Cambridge, 1991.

Ackerman, B., "Constitutional Politics/Constitutional Law", en Yale Law Journal, Vol. 99, 1989.

Baker, J., An Introduction to English Legal History, Butterworths, Londres, 1979.

Blanco, R., El valor de la Constitución. Separación de poderes, supremacía de la ley y control de constitucionalidad en los orígenes del Estado Liberal, Alianza Editorial, Madrid, 1994.

Brest, P. y otros, Processes of Constitutional Decisionmaking: Cases and Materials, York, 2000.

Carey, G., "El Federalista", en Revista Estudios Públicos, Santiago, No 13, 1987.

Craine, E., Publius in the Provinces: Where Was the Federalist Reprinted Outside New York City? Wm \& Mary Q., 1964.

DAHL, R., "Decision-Making in a Democracy: The Role of the Supreme Court as a National Policy-Maker", en Journal of Public Law, Vol. 6, 1957.

De Tocqueville, A., La democracia en América, Madrid, 1984.

Dietze, G., The Federalist: A Classic on Federalism and Free Government, John Hopkins Press, Baltimore, 1960.

Epstein, D., La Teoría Política de El Federalista, Grupo Editor Latinoamericana, Buenos Aires, 1990.

Friedman, M., Libertad de Elegir, Orbis, Madrid, 1983.

García, J. F., "El control de constitucionalidad en El Federalista y los fundamentos de una sociedad libre", en Revista Chilena de Derecho No 30, Vol. 3, 2003.

Hamilton, A. y отros, The Federalist Papers, Penguin, Nueva York, 1987.

Hamilton. A. y otros, El Federalista, Fondo de Cultura Económica (2ed.), México D.F., 2001.

HaYeK, F., Los Fundamentos de la Libertad, Unión Editorial, Madrid, 1991n

Kramer, L., "Foreword: We the Court", en Harvard Law Review, Vol. 115, 2001.

Kramer, L., The People Themselves: Popular Constitutionalism and Judicial Review, Oxford University Press, 2004. 
Ketcham, R., Escritos Antifederalistas y Debates de la Convención Constitucional de Estados Unidos, Hacer, Barcelona, 1996.

Liggio, L., "The Life and Works of Thomas Jefferson", en The Locke Luminary Vol. II, No 1 , Summer 1999 .

Mccloskey, R., The American Supreme Court, University of Chicago Press, Chicago, 2005.

McIilwain, C., Constitucionalismo antiguo y moderno, Centro de Estudios Constitucionales, Madrid, 1991.

Padover, S., The Complete Madison, Padover, Boston, 1953.

Rosenberg, G., "Judicial Independence and the Reality of Political Power", Review of Politics, Vol. 52, 1992.

SMITH, A., Investigación sobre la naturaleza y causas de la riqueza de las naciones, Fondo de Cultura Económica, México D.F., 1958.

STORY, J., Commentaries on the Constitution, Oakshott, Boston, 1933.

Sunstein, C. Y Otros, "Ideological Voting on Federal Courts of Appeals: A Preliminary Investigation”, en Virginia Law Review, Vol. 90, 2004. 
